\title{
Relative distribution and biological characterization of CXCL4L1 isoforms in platelets from healthy donors
}

Pieter Ruytinx ${ }^{1}$, Rik Janssens ${ }^{1}$, Nele Berghmans ${ }^{1}$, Mieke Gouwy ${ }^{1}$, Isabelle Ronsse ${ }^{1}$, Sandra Liekens ${ }^{2}$, Paul Proost ${ }^{1}$, Jo Van Damme ${ }^{1}$, Sofie Struyf ${ }^{1, *}$

$1 \mathrm{KU}$ Leuven, University of Leuven, Department of Microbiology and Immunology, Rega Institute for Medical Research, Laboratory of Molecular Immunology, B-3000 Leuven, Belgium

2 KU Leuven, University of Leuven, Department of Microbiology and Immunology, Rega Institute for Medical Research, Laboratory of Virology and Chemotherapy, B-3000 Leuven, Belgium

*Corresponding author: Sofie Struyf, Laboratory of Molecular Immunology, Rega Institute, KU Leuven, Herestraat 49 bus 1042, B-3000 Leuven, Belgium.

E-mail: sofie.struyf@kuleuven.be 


\section{Relative distribution and biological characterization of CXCL4L1 isoforms in platelets from healthy donors}

CXCL4L1, a platelet-derived ELR-negative CXC chemokine, is a powerful angiostatic and anti-tumoral chemokine. We developed a mass spectrometric assay for the detection of different natural CXCL4L1 isoforms. Using this assay, we identified 4 different CXCL4L1 isoforms in the supernatant of thrombin-stimulated platelets from healthy volunteers: the classical isoform CXCL4L1(1-70), CXCL4L1(-4-70), which probably arises through alternative signal peptide removal and two $\mathrm{COOH}$-terminally truncated isoforms CXCL4L1(1-69) and CXCL4L1(-4-69). CXCL4L1(1-70) was the most abundant isoform, whereas CXCL4L1(-4-70) was detected in 50\% of the platelet preparations. Since alterations to the $\mathrm{NH}_{2}$-terminus of chemokines can have severe biological consequences, we investigated the impact of the extension with $4 \mathrm{NH}_{2}$ terminal amino acids on the biological activity of CXCL4L1. In vitro, CXCL4L1(-4-70) was as potent as CXCL4L1(1-70) in inhibiting signal transduction and migration of human microvascular endothelial cells towards vascular endothelial growth factor (VEGF) and fibroblast growth factor-2 (FGF-2). In a FITC-conjugated dextran cell permeability assay, both splice variants showed a strong but comparable antipermeable effect upon VEGF stimulation of the endothelial cell monolayer. In vivo angiogenesis induced by FGF-2 was equally reduced by CXCL4L1(1-70) and CXCL4L1(-4-70). In chemotaxis assays with CXCR3A-transfected cells the CXCL4L1 isoforms both induced migration from $125 \mathrm{ng} / \mathrm{ml}$ onward. Finally, CXCL4L1(1-70) and CXCL4L1(-4-70) showed the same affinity for heparin. In conclusion, the investigated biological activities of CXCL4L1 are not influenced by the four extra $\mathrm{NH}_{2}$-terminal residues present in the alternatively spliced isoform CXCL4L1(-4-70). Therefore, our results suggest that both isoforms equally interact with the CXCR3A and CXCR3B receptor. 


\section{INTRODUCTION}

Chemokines are a family of chemotactic cytokines that regulate migration of leukocytes under physiological and pathological conditions [1-3]. Chemokines typically possess four conserved cysteine residues, which are essential for their tertiary structure [4]. Based on the number of conserved cysteine residues and their positioning, chemokines are classified into $\mathrm{CXC}, \mathrm{CC}, \mathrm{CX}_{3} \mathrm{C}$, and $\mathrm{C}$ subfamilies. The $\mathrm{CXC}$ chemokine ligands are further subdivided based on the presence or absence of the tripeptide Glu-Leu-Arg (the "ELR motif"), that precedes the first conserved cysteine. The ELR ${ }^{+} \mathrm{CXC}$ chemokines are angiogenic and are responsible for the recruitment and activation of neutrophils, whereas most ELR- CXC chemokines are angiostatic and mainly attract lymphocytes and natural killer cells $[5,6]$.

Chemokines exert their biological action through activation of seven transmembrane domain G-protein coupled receptors (GPCRs) but have also been shown to interact with glycosaminoglycan moieties such as heparan sulfate on the surface of endothelial cell layers [1]. Chemokine activity is regulated by different mechanisms, such as posttranslational modification of chemokines and their receptors [7, 8]. Citrullination [9], glycosylation [10, 11], nitration [12-14] and proteolytic processing at the $\mathrm{COOH}$ - and/or $\mathrm{NH}_{2}$-terminal regions of chemokines have been reported [15]. $\mathrm{NH}_{2}$-terminal proteolytic processing of CXC chemokines by aminopeptidases or endoproteases can alter the receptor specificity, resulting in up- or down-regulation of chemotactic or angiogenic activity [15-18]. Platelet factor-4 (PF-4)/CXCL4 was the first discovered chemokine and its amino acid sequence was published in 1977, by Deuel et al. [19]. The variant of CXCL4, encoded by a second non-allelic gene and designated PF-4var/CXCL4L1, was not isolated from thrombin-stimulated platelets until 2004 [20]. CXCL4 and CXCL4L1 differ only in three amino acids that are situated in their carboxy-terminal region (Pro ${ }^{58} \rightarrow$ Leu, Lys ${ }^{66} \rightarrow$ Glu, Leu ${ }^{67} \rightarrow$ His; CXCL4 $\rightarrow$ CXCL4L1) [21, 22]. CXCL4L1 was identified as a ten times more potent angiostatic chemokine than CXCL4. CXCL4L1 was shown to inhibit endothelial cell proliferation and migration, thereby reducing tumor growth and metastasis [23].

The chemotactic and angiostatic activity of CXCL4L1 is mediated by the two different splice variants of the CXC chemokine receptor 3, i.e. CXCR3A and CXCR3B, respectively [24]. Whereas CXCR3B is selectively expressed by endothelial cells [25], activated lymphocytes express both CXCR3A and CXCR3B. However, the 
chemotactic and proliferative aspects of CXCR3 ligands are believed to be mediated by CXCR3A, the first characterized CXCR3 isoform and coupling to a Gai protein [26]. In contrast CXCR3B reportedly signals via $\mathrm{G} \alpha \mathrm{s}$, leading to inhibition of migration and proliferation [25].

Including its signal-peptide, the full-length human CXCL4L1 is composed of 104 amino acids, whereas the mature monomeric protein contains 70 amino acids and has a theoretical $\mathrm{Mr}_{\mathrm{r}}$ of 7806.1. Besides this classical isoform of CXCL4L1, we discovered an $\mathrm{NH}_{2}$-terminally extended isoform of CXCL4L1 namely CXCL4L1(-4-70) with four additional amino acids at the $\mathrm{NH}_{2}$-terminal side, which probably arises through alternative signal peptide removal. In this study we wanted to identify all different $\mathrm{NH}_{2}$ terminally processed CXCL4L1 isoforms in the supernatant of thrombin-stimulated platelets from healthy persons and measure the levels of the two major isoforms CXCL4L1(1-70) and CXCL4L1(-4-70). Furthermore, the biological implication of this alternative signal peptide removal was investigated in different angiogenesis assays.

\section{MATERIALS AND METHODS}

\section{Sample preparation}

To identify CXCL4L1 isoforms, $40 \mathrm{ml}$ of blood was collected from 13 healthy volunteers and platelets were isolated as previously described [27]. All blood gave informed consent donors at the time of blood collection. The experimental procedure and the informed consent form were approved by the ethical committee of the University of Leuven. Information about the donors is provided in Table 1. The final pellet was resuspended in JNL-buffer (130 mM NaCl, $10 \mathrm{mM}$ trisodium citrate, $9 \mathrm{mM} \mathrm{NaHCO}, 6$ $\mathrm{mM}$ dextrose, $0.9 \mathrm{mM} \mathrm{MgCl}_{2}, 0.81 \mathrm{mM} \mathrm{KH}_{2} \mathrm{PO}_{4}, 10 \mathrm{mM}$ Tris, $\mathrm{pH}$ 7.4) supplemented with $1.8 \mathrm{mM} \mathrm{CaCl}_{2}$ and stimulated with $1 \mathrm{U} / \mathrm{ml}$ thrombin (Sigma, St. Louis, MO) for 30 min at $37^{\circ} \mathrm{C}$ in a warm water bath. After stimulation, the protease inhibitor cocktail for mammalian tissue (Sigma) was added, the lysate was centrifuged at $16200 \mathrm{~g}$ for 10 min at $4^{\circ} \mathrm{C}$ and the supernatant was collected.

To pre-purify the sample, a small scale CXCL4L1 antibody affinity purification column was prepared. Monoclonal antibodies against human CXCL4L1 were developed by immunizing mice with a COOH-terminal CXCL4L1 peptide coupled to ovalbumine [28]. Resulting hybridomas were positively selected for specific reactivity with human CXCL4L1, but excluded when cross-reactive with human CXCL4. The CXCL4L1- 
specific clone 3C7 (3 mg) was selected for coupling to CNBr-activated Sepharose (GE healthcare, Little Chalfont, United Kingdom). The obtained thrombin-stimulated platelet supernatant $(100 \mu \mathrm{l})$ was mixed with the CXCL4L1-coupled antibody matrix $(400 \mu \mathrm{l})$ and incubated for $15 \mathrm{~min}$ at room temperature. Afterwards the matrix was washed 3 times with wash buffer (ultrapure water containing $150 \mathrm{mM} \mathrm{NaCl}, 10 \mathrm{mM} \mathrm{L}$-methionine, 10 mM L-Alanine, 10 mM L-Leucine, 10 mM L-Histidine, 10 mM L-Proline, 10 mM LGlycine, $\mathrm{pH}$ 7.0). Elution of proteins was obtained by applying $150 \mu \mathrm{l}$ of elution buffer [wash buffer containing $50 \mathrm{mM}$ L-glycine (pH 2.0)] 4 consecutive times. The eluate was concentrated onto an Amicon Ultra-15 3 kDa Centrifugal Filter Unit (Sigma).

The concentrated samples were purified by reversed-phase ultra-high performance liquid chromatography (RP-UPLC) on an UltiMate 3000 RSLC nano system (Thermo Fisher Scientific, Waltham, MA). Samples were centrifuged at 10,000 gor $10 \mathrm{~min}$ and acidified with $1 \%$ trifluoroacetic acid (TFA; Biosolove, Valkenswaard, The Netherlands) prior to injection at a flow rate of $1.5 \mu \mathrm{l} / \mathrm{min}$ on a Proto $300 \mathrm{C} 4$ column, pore size $5 \mu \mathrm{m}$ (50 mm x $0.150 \mathrm{~mm}$; Higgins Analytical, Mountain View, CA) equilibrated with $0.1 \%$ $(\mathrm{v} / \mathrm{v})$ TFA and $4 \%(\mathrm{v} / \mathrm{v})$ acetonitrile in ultrapure water. Proteins were eluted in an acetonitrile gradient in $0.1 \%(\mathrm{v} / \mathrm{v})$ formic acid in ultrapure water and were immediately injected in an Amazon ETD electrospray ion trap mass spectrometer (Bruker, Bremen, Germany).

\section{Cell cultures}

For the in vitro angiogenesis assays we used primary human retinal microvascular endothelial cells (HMVEC; Cell systems, Kirkland, WA). HMVEC (passage number six to eight) were grown in endothelial basal medium-2 (EBM-2) supplemented with the endothelial growth medium-2 MV (EGM2-MV) bulletkit (Lonza, Verviers, Belgium). In addition, we used Chinese hamster ovary ( $\mathrm{CHO}$ ) cells, transfected with CXCR3A [29]. These CXCR3A-transfected $\mathrm{CHO}$ cells were cultivated in Ham's F-12 growth medium (Lonza) and supplemented with 10\% (v/v) FCS (Invitrogen, Merelbeke, Belgium) 400 $\mu \mathrm{g} / \mathrm{ml}$ geneticin (Invitrogen) and $1 \mathrm{mM}$ sodium pyruvate (Invitrogen).

\section{Recombinant human CXCL4L1(-4-70) and CXCL4L1(1-70) production}

To establish production of recombinant human CXCL4L1(-4-70) and CXCL4L1(1-70) by Sf9 insect cells, we used the Bac-to-Bac ${ }^{\circ}$ HBM TOPO ${ }^{\circledR}$ Secreted Expression 
System (as described and supplied by Invitrogen). The previously prepared CXCL4L1(1-70) expression vector [29] was mutated to introduce the 4 extra $\mathrm{NH}_{2-}$ terminal amino acids. Successful mutagenesis was confirmed through DNA sequencing. Pure recombinant human CXCL4L1(1-70) and CXCL4L1(-4-70) were obtained by using a three-step chromatographic procedure as described for purification of CXCL4L1 from Escherichia Coli [23]. Purity and molecular mass of both CXCL4L1 isoforms were verified by $\mathrm{NH}_{2}$-terminal amino acid sequencing and mass spectrometry. CXCL4L1 concentrations were determined by several techniques including enzyme-linked immunosorbent assay (ELISA) and the bicinchoninic acid (BCA, Pierce, Rockford, IL) assay.

\section{Heparin-Sepharose affinity chromatography}

A small-scale affinity column was prepared with heparin Sepharose 6 fast flow matrix (GE Healthcare). The column $(0.6 \times 5.0 \mathrm{~cm}, 1 \mathrm{ml}$ volume) was equilibrated with loading buffer [ultrapure $\mathrm{H}_{2} \mathrm{O}$ containing $50 \mathrm{mM}$ Tris- $\mathrm{HCl}$ and $50 \mathrm{mM} \mathrm{NaCl}, \mathrm{pH}$ 7.4] at a flow rate of $1 \mathrm{ml} / \mathrm{min}$. The two isoforms $(1.5 \mu \mathrm{g})$ were separately loaded on this column in loading buffer. CXCL4L1 was eluted using a multi-step $\mathrm{NaCl}$ gradient ranging from $0.05 \mathrm{M}$ to $2.0 \mathrm{M}$ in $50 \mathrm{mM}$ Tris- $\mathrm{HCl}, \mathrm{pH} 7.4$, at a flow rate of $1 \mathrm{ml} / \mathrm{min}$. Fractions of $1 \mathrm{ml}$ were collected during the first $30 \mathrm{~min}$ of the elution gradient (till $0.75 \mathrm{M} \mathrm{NaCl}$ ). Chemokine concentrations were assessed in these fractions by CXCL4L1 ELISA as described [30].

\section{Cell Permeability Assay}

HMVEC were seeded (10,000 cells/well) on gelatin-coated membranes with $0.4 \mu \mathrm{m}$ pores and 6.5 mm diameter (Transwell; Corning, New York, NY) in EBM-2 medium + EGM2-MV bulletkit and were grown to confluency. Cultures were then kept in starvation medium [EBM-2 medium enriched with $1 \%$ (v/v) FCS] overnight. Afterwards, cells were treated with $30 \mathrm{ng} / \mathrm{ml}$ of vascular endothelial growth factor (VEGF, BioLegend, San Diego, CA) in combination with $100 \mathrm{ng} / \mathrm{mL}$ of CXCL4L1(-470) or CXCL4L1(1-70) in the upper chambers for $3 \mathrm{~h}$. After treatment, $1 \mathrm{mg} / \mathrm{ml}$ Fluorescein isothiocyanate (FITC)-conjugated dextran (70 kDa; Sigma) was added to the top compartments. After 90 min, the amount of FITC-conjugated dextran in the bottom compartment was measured by fluorometry (excitation wavelength, $485 \mathrm{~nm}$; 
emission wavelength, $530 \mathrm{~nm}$ ) and corrected for the fluorescence reading of samples from the top compartment. Permeability is calculated as the amount of fluorescent tracer passing from the upper to the lower compartment.

\section{Cell migration}

The chemotactic activity of both CXCL4L1 isoforms for HMVEC was compared using cell invasion/migration (CIM) plates and the real-time cell analyzer double plate (RTCA-DP) xCELLigence instrument (Acea Biosciences, San Diego, CA). This system records changes of electrical impedance, which is reflected as Cell Index $(\mathrm{Cl})$ over a prolonged time course. First, $160 \mu \mathrm{l}$ of EBM-2 containing $0.4 \% \mathrm{FCS}$ (control medium) or control medium supplemented with $10 \mathrm{ng} / \mathrm{ml}$ of VEGF or $30 \mathrm{ng} / \mathrm{ml}$ of basic fibroblast growth factor (FGF-2; Sigma) was added to the lower chamber in the presence or absence of CXCL4L1(-4-70) or CXCL4L1(1-70) at different concentrations. After assembling the CIM chemotaxis chamber, $50 \mu \mathrm{l}$ of EBM-2 medium was added to the upper compartment. Subsequently, the CIM16-plate was left to equilibrate at room temperature for 1 hour. Afterwards, HMVECs (40,000 cells per well) were seeded in each well $(100 \mu / / w e l l)$ of the upper chamber in control medium and allowed to settle onto the membrane for $30 \mathrm{~min}$. After transfer to $\mathrm{a}_{2}$ incubator $\left(37^{\circ} \mathrm{C}\right)$, the impedance value was monitored every minute for $15 \mathrm{~h}$.

Cell migration of CHO-CXCR3A cells was also tested using the XCELLigence system according to the above-described procedure. Here, $160 \mu \mathrm{l}$ of Ham's F-12 medium supplemented with $2 \%(\mathrm{v} / \mathrm{v}) \mathrm{FCS}, 400 \mu \mathrm{g} / \mathrm{ml}$ geneticin and $1 \mathrm{mM}$ sodium pyruvate [Ham's control medium] or Ham's control medium containing CXCL4L1(1-70) and CXCL4L1(-4-70) at different concentrations was added to the lower chambers. The CHO-CXCR3A cells were diluted to a final concentration of $0.8 \times 10^{6} \mathrm{cell} / \mathrm{s} / \mathrm{ml}$ in Ham's control medium and chemotaxis was monitored during 20 hours. All experiments were performed in duplicate. Results are expressed as net cell indexes. Net cell indexes were calculated by subtracting the average cell index obtained in response to control medium from the cell index obtained for the chemoattractant.

\section{Signal transduction assay}

For each signal transduction assay, HMVEC were seeded in 6-well plates. Once cells reached a confluency level of $80 \%$ or more, the growth medium was removed and the 
cells were cultured overnight in starvation medium (EBM-2 medium without growth supplements). At least 15 min prior to stimulation the starvation medium was removed and $900 \mu \mathrm{l}$ prewarmed starvation medium supplemented with $0.5 \mathrm{~g} / 100 \mathrm{ml}$ bovine serum albumin (BSA; Sigma) was added. Tenfold dilutions of the inducers (FGF-2) with or without CXCL4L1(1-70) and CXCL4L1(-4-70) at different concentrations in EBM-2+0.5\% BSA were added to the plates and incubated for 5 min at $37^{\circ} \mathrm{C}$. Afterwards, cells were washed 3 times with ice-cold PBS and $100 \mu$ lysis buffer [6 M ureum, $1 \mathrm{mM}$ ethylenediaminetetraacetic acid (EDTA), 0.5\% (v/v) Triton X-100, protease inhibitor cocktail for mammalian tissues and phosphatase inhibitor cocktails 1 and 2 (Sigma) in PBS] was added. The lysates were kept on ice and cleared by centrifugation $\left(4^{\circ} \mathrm{C}, 10 \mathrm{~min}, 400 \mathrm{~g}\right)$. The amount of phosphorylated ERK1/2 in the supernatant was determined using specific ELISAs for phospho-ERK1 (T202/Y204)/ERK2 (T185/Y187) (duoset cat no. DYC1018B, R\&D Systems, Minneapolis, MN). Simultaneously, total protein content was determined in a BCA protein assay.

\section{In vivo Matrigel assay}

Animal experiments were approved by the Ethics Committee for Animal Care and Use of the University of Leuven and adhered to the international guidelines for animal ethics and welfare. Six- to 8-week-old healthy female C57BL/6 mice were injected subcutaneously with $0.5 \mathrm{ml}$ of growth-factor reduced (GFR) Matrigel (Corning ${ }^{\circledR}$ Matrigel $(\AA$ Basement Membrane Matrix GFR, Phenol Red Free; final concentration $10.4 \mathrm{mg} / \mathrm{ml}$ ) containing $300 \mathrm{ng} / \mathrm{ml} \mathrm{FGF-2} \mathrm{(Sigma)} \mathrm{and/or} 1$ mg/ml CXCL4L1(-4-70) or CXCL4L1(1-70). After 7 days mice were euthanized and Matrigel plugs were removed and photographed. Mice were sacrificed by intraperitoneal injection of an overdose of ketamine $(150 \mathrm{mg} / \mathrm{kg})$ and xylazine $(20 \mathrm{mg} / \mathrm{kg})$ prior to Matrigel plug isolation. After enzymatic digestion of the Matrigel plugs, endothelial cells in the Matrigel plugs were quantified by FACS analysis. Single cell suspensions were prepared using a MACS dissociator (Myltenyi Biotec; Bergisch Gladbach, Germany) and an enzymatic digestive mixture containing FCS (2\%), EDTA (2 mM), dispase (15 U) and DNase (10 $000 \mathrm{U}$ ) dissolved in $5 \mathrm{ml} \mathrm{PBS}$. After incubation for $1 \mathrm{~h}$ at $37^{\circ} \mathrm{C}$ in the digestive mixture, remaining cell clumps were removed by passing the cell suspension through a $70-\mu \mathrm{m}$ cell strainer. After centrifugation $\left(220 \mathrm{~g}, 10 \mathrm{~min}, 4^{\circ} \mathrm{C}\right)$, cells were resuspended in FACS buffer (PBS containing 2\% FCS and 2 mM EDTA). Flow cytometry was performed 
using a FACS Calibur and CellQuest software (BD Biosciences, San Jose, CA). Biotinylated anti-mouse mucosal vascular addressin cell adhesion molecule-1 (MADCAM-1) (Clone MECA-367, BD Bioscienses) and anti-mouse CD45-APC (Clone 30-F11, BD Bioscienses) were used to characterize the endothelial cell population.

\section{Statistical analysis}

Data are presented as mean \pm SEM. After 1-way non-parametric ANOVA analysis (Kruskal-Wallis test), the nonparametric Mann-Whitney $U$ test was used to perform post-hoc multiple comparisons. 


\section{RESULTS}

\section{Identification and relative distribution of natural human CXCL4L1}

In order to isolate and identify natural isoforms of CXCL4L1, platelets of healthy volunteers were stimulated with thrombin and the supernatant was prepurified by antibody-affinity chromatography. Since currently available ELISAs do not distinguish between different chemokine isoforms, mass spectrometry (MS) was used to identify and quantify possible CXCL4L1 variants. Mass spectrometrical analysis demonstrated the presence of four CXCL4L1 isoforms (Fig. 1A), namely intact CXCL4L1(1-70) with an average $\mathrm{Mr}_{\mathrm{r}}$ of 7805.8 (theoretical average $\mathrm{Mr}_{\mathrm{r}}$ of 7806.1) and the $\mathrm{COOH}$-terminally truncated CXCL4L1(1-69) with an average Mr of 7718.1 (theoretical average $\mathrm{Mr}$ of 7719.0). We also found an extended isoform of CXCL4L1, namely CXCL4L(-4-70) with an average $M_{r}$ of 8250.9 (theoretical average $M_{r}$ of 8251.6). In two out of 13 preparations from different donors we observed the $\mathrm{COOH}$-terminally truncated CXCL4L1(-4-69) isoform with an average $\mathrm{Mr}$ of 8164.8 (theoretical average $\mathrm{Mr}$ of 8164.5). Furthermore, we also found CXCL4 with an average Mr of 7764.2 (theoretical average $\mathrm{Mr}_{\mathrm{r}}$ of 7765.1).

The relative amounts of the different CXCL4L1 isoforms for every single donor are shown in Fig. 1B. The classical isoform CXCL4L1(1-70) was present in all donors and on average contributed to $50 \%$ of the total amount of CXCL4L1 produced by platelets. The COOH-terminally truncated isoform CXCL4L1(1-69) was found in almost every donor and was the second most abundant (35.1\%) isoform. Only in about half of the healthy volunteers we observed the extended isoform CXCL4L1(-4-70) and the abundance was lower compared to the classical CXCL4L1(1-70) isoform. The COOHterminally truncated CXCL4L1(-4-69) was detected in only two donors. The distribution of the different isoforms with their observed and theoretical $\mathrm{Mr}_{\mathrm{r}}$ together with their frequency is shown in Fig. $1 \mathrm{C}$.

\section{CXCL4L1(1-70) and CXCL4L1(-4-70) inhibit VEGF- and FGF-2-induced HMVEC migration}

To investigate the biological effect of both isoforms, CXCL4L1(1-70) and CXCL4L1(4-70) were produced recombinantly by Sf9 insect cells. Pure proteins were obtained by using a three-step procedure consisting of heparin-Sepharose chromatography, 
reversed-phase high-performance liquid chromatography (HPLC) and cation exchange chromatography as described [23]. Ion trap mass spectrometry was used to confirm that the recombinant CXCL4L1(1-70) was correctly expressed without any modifications (experimental average $\mathrm{Mr}_{\mathrm{r}}$ 7806.3; theoretical average $\mathrm{Mr}_{\mathrm{r}}$ 7806.1; Fig. 2A). The Mr of CXCL4L1(-4-70) was 8251.0 (theoretical average Mr 8251.6; Fig. 2B). Previously, we demonstrated that intact CXCL4L1 inhibits FGF-2-induced endothelial cell motility in the Boyden microchamber chemotaxis assay [23]. Using electrical impedance real-time cell analysis (RTCA) label-free monitoring of cell migration was performed. We investigated whether the intact and the $\mathrm{NH}_{2}$-terminally extended CXCL4L1 isoforms could counteract FGF-2-induced endothelial cell migration with different potency. As shown in Fig. 3A, FGF-2 (30 ng/ml) significantly stimulated endothelial cell migration to a net cell index of 1.00 or $93 \%$ above baseline (i.e., in the absence of chemotactic agent, EBM-2 medium supplemented with $0.4 \%$ FCS). When HMVEC were treated with FGF-2 in the presence of CXCL4L1(1-70) or CXCL4L1(-470), cell migration was reduced. Treatment with $1 \mu \mathrm{g} / \mathrm{ml}$ of CXCL4L1(1-70) reduced FGF-2-induced HMVEC migration (73\% inhibition). Similarly, after adding CXCL4L1($4-70)$ at $1 \mu \mathrm{g} / \mathrm{ml}$, FGF-2-induced migration was significantly inhibited (43\% inhibition). Nevertheless, no statistically significant difference between both isoforms was noted. Next, we stimulated HMVEC with another prominent pro-angiogenic factor, VEGF. As expected, VEGF $(10 \mathrm{ng} / \mathrm{ml})$ induced a significant chemotactic response of HMVEC. When VEGF was added together with the CXCL4L1 isoforms, endothelial cell migration was attenuated. Only at the highest concentration tested, i.e. at $1 \mu \mathrm{g} / \mathrm{ml}$, both CXCL4L1 isoforms significantly inhibited VEGF-induced cell migration (Fig. 3B), without any significant difference between both isoforms.

\section{CXCL4L1(1-70) and CXCL4L1(-4-70) counteract FGF-2-induced ERK phosphorylation}

Other groups reported that CXCL4 could inhibit FGF-2-induced extracellular signalregulated kinase (ERK) phosphorylation [31]. Therefore, we also assessed the ability of both CXCL4L1 isoforms to block FGF-2-induced ERK signal transduction pathways. FGF-2 $(10 \mathrm{ng} / \mathrm{ml})$ significantly elevated the phosphorylation status of ERK within $5 \mathrm{~min}$ to $198 \pm 13 \%$ compared to control (100 $\pm 6 \%$ ) (Fig. 4). CXCL4L1(1-70) and CXCL4L1(4-70) significantly reduced FGF-2-induced phosphorylation to $131 \pm 14 \%$ and $160 \pm$ 
$20 \%$ respectively. We found no significant difference between both isoforms in blocking FGF-2-induced ERK signal transduction.

\section{CXCL4L1(1-70) and CXCL4L1(-4-70) neutralize VEGF-induced permeability in HMVEC}

Since it was already shown by our group that CXCL4L1(1-70) inhibits VEGF-induced endothelial cell permeability [32], we compared both isoforms for their anti-permeable effect. Exposure of HMVEC to VEGF (30 ng/ml), resulted in a significant increase in FITC leakage through the confluent cell monolayer within 90 min (Fig. 5). We found that cotreatment of HMVEC with CXCL4L1(-4-70) $(100 \mathrm{ng} / \mathrm{ml})$ or CXCL4L1(1-70) (100 $\mathrm{ng} / \mathrm{ml}$ ) and VEGF significantly inhibited VEGF-induced permeability. Again no statistically significant difference between CXCL4L1(1-70) and CXCL4L1(-4-70) was detected.

\section{CXCL4L1(1-70) and CXCL4L1(-4-70) equally inhibit FGF-2-induced in vivo angiogenesis}

To investigate the in vivo angiostatic activity of both CXCL4L1 isoforms, we performed a Matrigel plug assay. Matrigel plugs containing $300 \mathrm{ng} / \mathrm{ml}$ of FGF-2 alone or combined with CXCL4L1(-4-70) $(1 \mu \mathrm{g} / \mathrm{ml})$ or CXCL4L1(1-70) $(1 \mu \mathrm{g} / \mathrm{ml})$ were implanted subcutaneously at the dorsal side of the mouse. Representative images of the plugs are shown in Fig. 6A.

FGF-2 $(300 \mathrm{ng} / \mathrm{ml})$ induced new blood vessel formation in the Matrigel plug seven days after implantation. CXCL4L1(-4-70) $(1 \mu \mathrm{g} / \mathrm{ml})$ and CXCL4L1(1-70) $(1 \mu \mathrm{g} / \mathrm{ml})$ almost completely suppressed FGF-2-induced angiogenesis, since Matrigel plugs looked more transparent. The macroscopically observed changes in vessel formation in the plugs were confirmed by flow cytometric analysis of single cells liberated from Matrigel plugs after staining for surface expression of CD45 and MADCAM1, a hematopoietic and endothelial cell marker, respectively. The CD45-MADCAM ${ }^{+}$endothelial cell population was significantly increased upon addition of FGF-2 to the Matrigel from 17 $\pm 2 \%$ to $29 \pm 4 \%$. When CXCL4L1(1-70) $(1 \mu \mathrm{g} / \mathrm{ml})$ or CXCL4L1 $(-4-70)(1 \mu \mathrm{g} / \mathrm{ml})$ was added to the plugs, the CD45/MADAM ${ }^{+}$cell population was significantly decreased to $19 \pm 4 \%$ and $21 \pm 1 \%$, respectively (Fig. 6B) which is in line with the macroscopic observations. 
CXCL4L1(1-70) and CXCL4L1(-4-70) equally induce chemotaxis of CXCR3Atransfected cells

On primary microvascular endothelial cells CXCR3B is selectively expressed [25] and data not shown. To investigate whether CXCL4L1(1-70) and CXCL4L1(-4-70) interact differently with CXCR3A, chemotaxis experiments were performed with $\mathrm{CHO}$ cells transfected with CXCR3A. Those cells were stimulated with CXCL4L1(1-70) and CXCL4L1(-4-70) at 8, 32, 125 and $500 \mathrm{ng} / \mathrm{ml}$ and migration was recorded overnight (Fig. 7). Compared to control medium, significant (net cell index >0.2) migration of $\mathrm{CHO} / \mathrm{CXCR} 3 \mathrm{~A}$ cells was induced by both isoforms from $125 \mathrm{ng} / \mathrm{ml}$ onward. However, no statistically significant difference between CXCL4L1(1-70) and CXCL4L1(-4-70) was found.

\section{CXCL4L1(1-70) and CXCL4L1(-4-70) display similar heparin-binding affinity}

Finally, we verified whether the two CXCL4L1 isoforms show different binding affinity for heparin. We prepared a small-scale heparin-Sepharose column and separately loaded $1.5 \mu \mathrm{g}$ of the two isoforms on this column in two consecutive runs. After elution of the chemokines in a $\mathrm{NaCl}$ gradient, fractions were analyzed by a specific CXCL4L1 ELISA, that equally detects CXCL4L1(1-70) and CXCL4L1(-4-70). Fig. 8 illustrates that CXCL4L1(1-70) and CXCL4L1(-4-70) eluted at exactly the same $\mathrm{NaCl}$ concentration $(0.5 \mathrm{M} \mathrm{NaCl})$ in the elution gradient, namely in fractions 18 to 26 . For both isoforms fraction 22 contained the highest CXCL4L1 concentration. We therefore concluded that there is no difference in heparin-binding between the two isoforms. 


\section{DISCUSSION}

CXCL4L1 isolated from thrombin-stimulated platelets has been described to be a strong inhibitor of angiogenesis [20]. So far, only the classical isoform of CXCL4L1, i.e. CXCL4L1(1-70) has been studied. In this study the extended isoform of CXCL4L1, i.e. CXCL4L1(-4-70) has also been biologically characterized. This elongated form is presumed to arise through alternative cleavage of the signal peptide from the 104 amino acid precursor, as predicted by SignalP (SignalP 4.1 Server) [33] and SignalBLAST [34]. Therefore, we first investigated the relative amount of both isoforms in the supernatant of thrombin-stimulated platelets. To reach that goal, blood platelets were isolated from healthy volunteers and upon thrombin stimulation, the supernatant was prepurified and CXCL4L1 isoforms were analyzed by mass-spectrometry.

As a result, we identified four CXCL4L1 isoforms. Besides the classical isoform CXCL4L1(1-70) and the $\mathrm{NH}_{2}$-terminally extended CXCL4L1(-4-70), we also found two COOH-terminally processed isoforms of CXCL4L1, namely CXCL4L1(1-69) and CXCL4L1(-4-69). CXCL4L1(1-70) was the most abundant isoform, whereas the extended CXCL4L1(-4-70) was detected only in half of the cases and was present at lower levels compared to the classical isoform. In addition, we found traces of intact CXCL4. In a previous report by Kim et al. seven different isoforms of CXCL4 were identified in human serum using mass spectrometry [35], including the equivalent extended isoform of CXCL4, CXCL4(-4-70). However, the biological effect of these different $\mathrm{NH}_{2}$-terminally truncated isoforms was not further investigated. We also identified CXCL4(-4-70) in large batches of stimulated platelets (data not shown), wherein CXCL4(-4-70) represented a rather small proportion of the total CXCL4 amount. Gupta et al. identified a CXCL4 derivative that is generated by peptide bond cleavage between threonine-16 and serine-17. The $\mathrm{NH}_{2}$-terminally truncated CXCL4 isoform showed a 30- to 50-fold stronger growth inhibitory activity on endothelial cells compared to intact CXCL4 [36].

Using recombinant protein, the biological effect of the extension with four amino acids at the $\mathrm{NH}_{2}$-terminal side of CXCL4L1 was verified in several assays. Using the $x$ CELLigence system it was shown that the extension did not significantly affect the inhibitory activity on FGF-2- or VEGF-induced migration of microvascular endothelial cells. In addition, CXCL4L1(1-70) and CXCL4L1(-4-70) both inhibited VEGF-induced 
permeability. Further evaluation of signal transduction pathways showed that both CXCL4L1 isoforms were able to block FGF-2-induced-ERK-phosphorylation in endothelial cells to the same extent. In the in vivo Matrigel plug assay, both isoforms equally inhibited FGF-2-induced vascularization. Finally, the migratory response of CXCR3A-transfected cells to CXCL4L1(1-70) and CXCL4L1(-4-70) was similar. We can conclude that the four additional $\mathrm{NH}_{2}$-terminal amino acids do not affect the interaction of CXCL4L1 with CXCR3. Binding of CXCL4L1 to the CXCR3 receptor and activation of underlying signaling pathways was already shown in previous work by our group [29]. We also verified whether this extension of the $\mathrm{NH}_{2}$-terminus of CXCL4L1 affects binding to glycosaminoglycans (GAGs) and could not detect a difference in heparin-binding affinity.

Chemokine activity can be regulated at multiple levels. In the past, it has been shown that post-translational modifications, mainly proteolytic processing at the $\mathrm{NH}_{2}$-terminal region can affect biological activity. For instance, proteolytic processing of CXCL1, CXCL3, CXCL5 and CXCL8 in front of the ELR motif enhances the neutrophilactivating potency of these CXC chemokines $[15,37,38]$. In contrast, removal of up to eight $\mathrm{NH}_{2}$-terminal amino acids from human CXCL6 has no biological implication [39, 40]. The CXCL7 precursor platelet basic protein even requires extensive $\mathrm{NH}_{2}$-terminal truncation to obtain receptor signaling and chemotactic properties [17]. The IFN- $\gamma-$ inducible CXCR3 ligands lose chemotactic but not angiostatic activity through removal of two $\mathrm{NH}_{2}$-terminal residues. Interestingly, more profound proteolytic processing of CXCL10 resulted in loss of angiostatic properties [16]. In addition, some chemokines exist in different $\mathrm{NH}_{2}$-terminal isoforms due to alternative cleavage of the signal peptide and those isoforms might display distinct biological activity. Indeed, it was already shown that CXCL8(-2-77) is more potent compared to intact CXCL8(1-77) in signaling and in vitro chemotaxis assays with peripheral blood-derived human neutrophils. Despite the observed differences in the in vitro assays, no difference in neutrophil recruitment potency was detected between CXCL8(-2-77) and CXCL8(1-77) upon intraperitoneal injection in mice [41]. Besides $\mathrm{NH}_{2}$-terminal processing of chemokines, $\mathrm{COOH}$-terminal processing has been described on chemokines, although this has been studied in less detail [42]. Davis et al. reported that carboxypeptidase N (CPN) is responsible for the removal of the lysine residue at the $\mathrm{COOH}$-terminal side of CXCL12 $\alpha$ in plasma and serum. Removal of the lysine residue resulted in a significant decreased chemotactic activity and reduced pre-B-cell growth factor activity [43]. 
To provide physiologically relevant data we isolated the different isoforms from supernatants of freshly isolated blood platelets stimulated with thrombin. Indeed, this stimulation mimics the process of blood coagulation during which platelets are known to release their content. Supernatants were collected 30 minutes after stimulation, meaning that no de novo production could occur, but that the content of granules was released. Thus, the longer CXCL4L1(-4-70) isoform must be constitutively present in the platelets. To answer the question whether the expression of the alternatively spliced isoform of CXCL4L1 is a tissue-, cell- or inducer-specific phenomenon, we need to detect individual CXCL4L1 isoforms selectively. In this study, we used platelets as cellular source since these are the best producers of CXCL4L1. CXCL4L1 levels in circulation or produced by e.g. tumor cells are much lower and levels are too low to allow identification of the isoforms by the procedure described here. An alternative solution would be the development of monoclonal antibodies specifically detecting CXCL4L1(-4-70), which is not evident because it is highly similar to CXCL4(-4-70) and CXCL4L1(1-70). It would be interesting though to compare the CXCL4L1 signature from patients with that of healthy controls. We already provided evidence that patients with stable coronary artery disease have a worse prognosis when CXCL4L1 levels in the serum are low [44]. However, knowledge on possible pathological roles of CXCL4L1 is still limited, in contrast to its anti-angiogenic therapeutic potential which has been confirmed by others [6, 32, 45-47]. 
Fig. 1 Identification of CXCL4L1 isoforms in supernatants of platelets by mass spectrometry

Unprocessed mass spectrum from the prepurified platelet supernatant of one representative donor with the ion intensities, the number of charges and the corresponding mass over charge ratio $(\mathrm{m} / \mathrm{z})$ for multiple charged ions indicated on the $X$-axis (A). A, B, C, D and $E$ represent the different isoforms: CXCL4L1(1-69), CXCL4, CXCL4L1(1-70), CXCL4L1(-4-70) and CXCL4L1(-4-69), respectively.

The relative distribution of CXCL4L1 isoforms in thrombin-stimulated platelets from 13 healthy volunteers was calculated (B). The table (C) depicts the observed and theoretical $\mathrm{Mr}_{\mathrm{r}}$ of each CXCL4L1 isoform and the absolute and relative number of individuals in which the isoform was detected.

Fig. 2 Quality control by mass spectrometry of recombinant CXCL4L1(1-70) and CXCL4L1(-4-70)

CXCL4L1(1-70) (A) and CXCL4L1(-4-70) (B) were produced recombinantly and purified using heparin-Sepharose, RP-HPLC and cation-exchange chromatography. CXCL4L1-containing fractions were selected by ELISA and pooled. The spectra of these pools are shown with the ion intensities, the number of charges and the corresponding mass over charge ratio $(\mathrm{m} / \mathrm{z})$ for multiple charged ions. The deconvoluted mass spectrum, as calculated by the Bruker deconvolution software, with the $\mathrm{Mr}$ of the uncharged proteins is shown as insert.

Fig. 3 CXCL4L1(1-70) and CXCL4L1(-4-70) inhibit FGF-2- and VEGF-induced HMVEC migration

HMVEC were stimulated with basal medium (CO), $30 \mathrm{ng} / \mathrm{ml}$ of FGF-2 (A) or $10 \mathrm{ng} / \mathrm{ml}$ VEGF (B) alone or in the presence of CXCL4L1(1-70) or CXCL4L1(-4-70) at the indicated concentrations. Cell index values were continuously measured for $15 \mathrm{~h}$ at intervals of 1 min using the xCELLigence RCTA DP system. Data represent average net cell indexes $\left( \pm\right.$ SEM) of 5 independent experiments ( ${ }^{*} p<0.05$; Mann-Whitney $U$ test versus FGF-2 or VEGF; ${ }^{\dagger} p<0.05$ Mann-Whitney $U$ test versus CO).

Fig. 4 CXCL4L1(1-70) and CXCL4L1(-4-70) counteract FGF-2-induced ERK phosphorylation in HMVEC. 
Phosphorylation of ERK was evaluated after a 5 min stimulation of HMVEC with FGF2 (10 ng/ml) or FGF-2 (10 ng/ml) in the presence of CXCL4L1(1-70) or CXCL4L1(-470) at 30, 100 or $300 \mathrm{ng} / \mathrm{ml}$. The ratio of phospho-ERK/total protein content was calculated for all cell lysates. Results (mean \pm SEM) are shown relative to the phosphorylation status of the secondary messenger in unstimulated cells. $n=6 ;{ }^{\dagger} p<0.05$ (Mann-Whitney test versus CO); ${ }^{*} \mathrm{p}<0.05$ (Mann-Whitney test versus FGF-2)

Fig. 5 CXCL4L1(1-70) and CXCL4L1(-4-70) inhibit VEGF-induced endothelial cell layer permeability

HMVEC were seeded in the upper compartment of a Transwell chamber, grown until confluency and starved overnight in 1\% FCS-containing medium. Monolayers were left untreated (CO) or stimulated with VEGF (30 ng/ml) or VEGF (30 ng/ml) plus $100 \mathrm{ng} / \mathrm{ml}$ CXCL4L1(1-70) or CXCL4L1(-4-70). Afterwards, FITC-conjugated dextran (1 mg/mL) was added and aliquots of the upper and lower compartment were assessed for fluorescence intensity. Data represent mean \pm SEM of 5 independent experiments $\left({ }^{*} p<0.05\right.$; Mann-Whitney $U$ test versus VEGF; ${ }^{\dagger} p<0.05$; Mann-Whitney $U$ test versus $\mathrm{CO})$.

Fig. 6 CXCL4L1(1-70) and CXCL4L1(-4-70) inhibit FGF-2-induced in vivo angiogenesis

Mice were randomly divided into 4 groups and received subcutaneously either Matrigel only, Matrigel + FGF-2 (300 ng/ml) or Matrigel+FGF-2 with CXCL4L1(1-70) or CXCL4L1(-4-70) at $1 \mu \mathrm{g} / \mathrm{ml}$.

Matrigel plugs were removed seven days after implantation and photographed for blood vessel formation $(A)$. These plugs were subjected to enzymatic digestion, liberated cells were stained with anti-CD45 (hematopoietic cells) and anti-MADCAM1 (endothelial cells) antibodies and analyzed by flow cytometry, thereby gating endothelial cells as the CD45/MADCAM ${ }^{+}$population (B). Data represent mean \pm SEM. ( $n=10$ mice/group; ${ }^{\star} p<0.05$; Mann-Whitney $U$ test versus FGF-2; ${ }^{\dagger} p<0.05$; MannWhitney $\mathrm{U}$ test versus $\mathrm{CO}$ )

Fig. 7 CXCL4L1(1-70) and CXCL4L1(-4-70) stimulate migration of CHO/CXCR3A cells 
$\mathrm{CHO}$ cells transfected with CXCR3A were stimulated with basal medium (CO), CXCL4L1(1-70) or CXCL4L1(-4-70) at the indicated concentrations (8-500 $\mathrm{ng} / \mathrm{ml})$. Cell indexes were continuously measured for $20 \mathrm{~h}$ at intervals of 1 min using the xCELLIgence RCTA DP system. Data are shown as net cell indexes (mean \pm SEM) of 5 independent experiments. ${ }^{*} p<0.05$ (Mann-Whitney $U$ test versus $\mathrm{CO}$ )

Fig. 8 Heparin-binding properties of CXCL4L1(1-70) and CXCL4L1(-4-70)

CXCL4L1(1-70) and CXCL4L1(-4-70) were loaded separately on a small-scale heparin-Sepharose column in two consecutive runs. CXCL4L1(-4-70) (bullets, dotted line) and CXCL4L1(1-70) (diamonds) were eluted using a multi-step sodium chloride gradient (dashed line). The CXCL4L1 concentration in each fraction was determined using ELISA. 
Table 1

Donor characteristics

\begin{tabular}{llll}
\hline Donor & Sex & Race & Age \\
\hline 1 & F & Caucasian & 25 \\
2 & F & Caucasian & 36 \\
3 & F & Caucasian & 26 \\
4 & M & Caucasian & 25 \\
5 & M & Caucasian & 26 \\
6 & M & Caucasian & 26 \\
7 & F & Caucasian & 25 \\
8 & F & Caucasian & 39 \\
9 & F & Caucasian & 40 \\
10 & F & Caucasian & 26 \\
11 & F & Caucasian & 39 \\
12 & F & Caucasian & 33 \\
13 & F & Caucasian & 65 \\
\hline
\end{tabular}




\section{Acknowledgements}

The authors would like to thank Noëmie Pörtner, Lotte Vanbrabant and Erik Martens for excellent technical assistance. We thank Prof. J. Van Snick (Ludwig Institute for Cancer Research, Brussels Branch, Brussels, Belgium) for preparation of CXCL4L1 peptide/OVA multimers that were used for the development of specific anti-CXCL4L1 monoclonal antibodies. This work was supported by the Interuniversity Attraction Poles Programme initiated by the Belgian Science Policy Office (I.A.P. Project 7/40), the Fund for Scientific Research of Flanders (FWO-Vlaanderen) and C1 funding of the KU Leuven.

\section{Ethical standards and conflict of interest}

Design and execution of all experiments are compliant with current legal requirements as stated by Belgian law. The authors declare that they have no conflict of interest. 


\section{References}

1. Struyf, S., P. Proost, and J. Van Damme, Regulation of the immune response by the interaction of chemokines and proteases. Adv Immunol, 2003. 81: p. 1-44.

2. Griffith, J.W., C.L. Sokol, and A.D. Luster, Chemokines and chemokine receptors: positioning cells for host defense and immunity. Annu Rev Immunol, 2014. 32: p. 659-702.

3. Anders, H.J., P. Romagnani, and A. Mantovani, Pathomechanisms: homeostatic chemokines in health, tissue regeneration, and progressive diseases. Trends Mol Med, 2014. 20(3): p. 15465.

4. Zlotnik, A. and O. Yoshie, Chemokines: a new classification system and their role in immunity. Immunity, 2000. 12(2): p. 121-7.

5. Strieter, R.M., P.J. Polverini, S.L. Kunkel, D.A. Arenberg, M.D. Burdick, J. Kasper, et al., The functional role of the ELR motif in CXC chemokine-mediated angiogenesis. J Biol Chem, 1995. 270(45): p. 27348-57.

6. Van Raemdonck, K., P.E. Van den Steen, S. Liekens, J. Van Damme, and S. Struyf, CXCR3 ligands in disease and therapy. Cytokine Growth Factor Rev, 2015. 26(3): p. 311-27.

7. Moelants, E.A., A. Mortier, J. Van Damme, and P. Proost, In vivo regulation of chemokine activity by post-translational modification. Immunol Cell Biol, 2013. 91(6): p. 402-7.

8. Stone, M.J., J.A. Hayward, C. Huang, E.H. Z, and J. Sanchez, Mechanisms of Regulation of the Chemokine-Receptor Network. Int J Mol Sci, 2017. 18(2).

9. Proost, P., T. Loos, A. Mortier, E. Schutyser, M. Gouwy, S. Noppen, et al., Citrullination of CXCL8 by peptidylarginine deiminase alters receptor usage, prevents proteolysis, and dampens tissue inflammation. J Exp Med, 2008. 205(9): p. 2085-97.

10. Jiang, Y., L.A. Tabak, A.J. Valente, and D.T. Graves, Initial characterization of the carbohydrate structure of MCP-1. Biochem Biophys Res Commun, 1991. 178(3): p. 1400-4.

11. Proost, P., F. Mahieu, E. Schutyser, and J. Van Damme, Posttranslational processing of chemokines. Methods Mol Biol, 2004. 239: p. 27-44.

12. Barker, C.E., S. Thompson, G. O'Boyle, H. Lortat-Jacob, N.S. Sheerin, S. Ali, et al., CCL2 nitration is a negative regulator of chemokine-mediated inflammation. Sci Rep, 2017. 7: p. 44384.

13. Molon, B., S. Ugel, F. Del Pozzo, C. Soldani, S. Zilio, D. Avella, et al., Chemokine nitration prevents intratumoral infiltration of antigen-specific T cells. J Exp Med, 2011. 208(10): p. 1949-62.

14. Janssens, R., A. Mortier, D. Boff, V. Vanheule, M. Gouwy, C. Franck, et al., Natural nitration of CXCL12 reduces its signaling capacity and chemotactic activity in vitro and abrogates intraarticular lymphocyte recruitment in vivo. Oncotarget, 2016. 7(38): p. 62439-62459.

15. Hebert, C.A., F.W. Luscinskas, J.M. Kiely, E.A. Luis, W.C. Darbonne, G.L. Bennett, et al., Endothelial and leukocyte forms of IL-8. Conversion by thrombin and interactions with neutrophils. J Immunol, 1990. 145(9): p. 3033-40.

16. Proost, P., E. Schutyser, P. Menten, S. Struyf, A. Wuyts, G. Opdenakker, et al., Amino-terminal truncation of CXCR3 agonists impairs receptor signaling and lymphocyte chemotaxis, while preserving antiangiogenic properties. Blood, 2001. 98(13): p. 3554-61.

17. Walz, A., B. Dewald, V. von Tscharner, and M. Baggiolini, Effects of the neutrophil-activating peptide NAP-2, platelet basic protein, connective tissue-activating peptide III and platelet factor 4 on human neutrophils. J Exp Med, 1989. 170(5): p. 1745-50.

18. Mortier, A., T. Loos, M. Gouwy, I. Ronsse, J. Van Damme, and P. Proost, Posttranslational modification of the NH2-terminal region of CXCL5 by proteases or peptidylarginine Deiminases (PAD) differently affects its biological activity. J Biol Chem, 2010. 285(39): p. 29750-9.

19. Deuel, T.F., P.S. Keim, M. Farmer, and R.L. Heinrikson, Amino acid sequence of human platelet factor 4. Proc Natl Acad Sci U S A, 1977. 74(6): p. 2256-8. 
20. Struyf, S., M.D. Burdick, P. Proost, J. Van Damme, and R.M. Strieter, Platelets release CXCL4L1, a nonallelic variant of the chemokine platelet factor-4/CXCL4 and potent inhibitor of angiogenesis. Circ Res, 2004. 95(9): p. 855-7.

21. Eisman, R., S. Surrey, B. Ramachandran, E. Schwartz, and M. Poncz, Structural and functional comparison of the genes for human platelet factor 4 and PF4alt. Blood, 1990. 76(2): p. 33644.

22. Green, C.J., R.S. Charles, B.F. Edwards, and P.H. Johnson, Identification and characterization of PF4varl, a human gene variant of platelet factor 4. Mol Cell Biol, 1989. 9(4): p. 1445-51.

23. Struyf, S., M.D. Burdick, E. Peeters, K. Van den Broeck, C. Dillen, P. Proost, et al., Platelet factor-4 variant chemokine CXCL4L1 inhibits melanoma and lung carcinoma growth and metastasis by preventing angiogenesis. Cancer Res, 2007. 67(12): p. 5940-8.

24. Struyf, S., L. Salogni, M.D. Burdick, J. Vandercappellen, M. Gouwy, S. Noppen, et al., Angiostatic and chemotactic activities of the CXC chemokine CXCL4L1 (platelet factor- 4 variant) are mediated by CXCR3. Blood, 2011. 117(2): p. 480-8.

25. Lasagni, L., M. Francalanci, F. Annunziato, E. Lazzeri, S. Giannini, L. Cosmi, et al., An alternatively spliced variant of CXCR3 mediates the inhibition of endothelial cell growth induced by IP-10, Mig, and I-TAC, and acts as functional receptor for platelet factor 4. J Exp Med, 2003. 197(11): p. 1537-49.

26. Mueller, A., A. Meiser, E.M. McDonagh, J.M. Fox, S.J. Petit, G. Xanthou, et al., CXCL4-induced migration of activated $T$ lymphocytes is mediated by the chemokine receptor CXCR3. J Leukoc Biol, 2008. 83(4): p. 875-82.

27. Di Michele, M., C. Goubau, E. Waelkens, C. Thys, R. De Vos, L. Overbergh, et al., Functional studies and proteomics in platelets and fibroblasts reveal a lysosomal defect with increased cathepsin-dependent apoptosis in ATP1A3 defective alternating hemiplegia of childhood. J Proteomics, 2013. 86: p. 53-69.

28. Uyttenhove, C., B. Arendse, V. Stroobant, F. Brombacher, and J. Van Snick, Development of an anti-IL-12 p40 auto-vaccine: protection in experimental autoimmune encephalomyelitis at the expense of increased sensitivity to infection. Eur J Immunol, 2004. 34(12): p. 3572-81.

29. Van Raemdonck, K., M. Gouwy, S.A. Lepers, J. Van Damme, and S. Struyf, CXCL4L1 and CXCL4 signaling in human lymphatic and microvascular endothelial cells and activated lymphocytes: involvement of mitogen-activated protein (MAP) kinases, Src and p70S6 kinase. Angiogenesis, 2014. 17(3): p. 631-40.

30. Vandercappellen, J., S. Noppen, H. Verbeke, W. Put, R. Conings, M. Gouwy, et al., Stimulation of angiostatic platelet factor-4 variant (CXCL4L1/PF-4var) versus inhibition of angiogenic granulocyte chemotactic protein-2 (CXCL6/GCP-2) in normal and tumoral mesenchymal cells. J Leukoc Biol, 2007. 82(6): p. 1519-30.

31. Sulpice, E., M. Bryckaert, J. Lacour, J.O. Contreres, and G. Tobelem, Platelet factor 4 inhibits FGF2-induced endothelial cell proliferation via the extracellular signal-regulated kinase pathway but not by the phosphatidylinositol 3-kinase pathway. Blood, 2002. 100(9): p. 308794.

32. Abu El-Asrar, A.M., G. Mohammad, M.I. Nawaz, M. Abdelsaid, M.M. Siddiquei, K. Alam, et al., The Chemokine Platelet Factor-4 Variant (PF-4var)/CXCL4L1 Inhibits Diabetes-Induced BloodRetinal Barrier Breakdown. Invest Ophthalmol Vis Sci, 2015. 56(3): p. 1956-64.

33. Petersen, T.N., S. Brunak, G. von Heijne, and H. Nielsen, SignalP 4.0: discriminating signal peptides from transmembrane regions. Nat Methods, 2011. 8(10): p. 785-6.

34. Frank, K. and M.J. Sippl, High-performance signal peptide prediction based on sequence alignment techniques. Bioinformatics, 2008. 24(19): p. 2172-6.

35. Kim, J.Y., J.R. Lee, S. Choi, E.M. Kim, N.K. Jung, Y.H. Kim, et al., Quantitative pattern analysis of the $\mathrm{N}$-terminally processed isoforms of platelet factor-4 in serum. Rapid Commun Mass Spectrom, 2013. 27(4): p. 521-30. 
36. Gupta, S.K., T. Hassel, and J.P. Singh, A potent inhibitor of endothelial cell proliferation is generated by proteolytic cleavage of the chemokine platelet factor 4. Proc Natl Acad Sci U S A, 1995. 92(17): p. 7799-803.

37. Wuyts, A., C. Govaerts, S. Struyf, J.P. Lenaerts, W. Put, R. Conings, et al., Isolation of the CXC chemokines ENA-78, GRO alpha and GRO gamma from tumor cells and leukocytes reveals NH2-terminal heterogeneity. Functional comparison of different natural isoforms. Eur J Biochem, 1999. 260(2): p. 421-9.

38. King, A.G., K. Johanson, C.L. Frey, P.L. DeMarsh, J.R. White, P. McDevitt, et al., Identification of unique truncated KC/GRO beta chemokines with potent hematopoietic and anti-infective activities. J Immunol, 2000. 164(7): p. 3774-82.

39. Van Den Steen, P.E., A. Wuyts, S.J. Husson, P. Proost, J. Van Damme, and G. Opdenakker, Gelatinase B/MMP-9 and neutrophil collagenase/MMP-8 process the chemokines human GCP-2/CXCL6, ENA-78/CXCL5 and mouse GCP-2/LIX and modulate their physiological activities. Eur J Biochem, 2003. 270(18): p. 3739-49.

40. Proost, P., C. De Wolf-Peeters, R. Conings, G. Opdenakker, A. Billiau, and J. Van Damme, Identification of a novel granulocyte chemotactic protein (GCP-2) from human tumor cells. In vitro and in vivo comparison with natural forms of GRO, IP-10, and IL-8. J Immunol, 1993. 150(3): p. 1000-10.

41. Mortier, A., N. Berghmans, I. Ronsse, K. Grauwen, S. Stegen, J. Van Damme, et al., Biological activity of CXCL8 forms generated by alternative cleavage of the signal peptide or by aminopeptidase-mediated truncation. PLoS One, 2011. 6(8): p. e23913.

42. Proost, P., S. Struyf, and J. Van Damme, Natural post-translational modifications of chemokines. Biochem Soc Trans, 2006. 34(Pt 6): p. 997-1001.

43. Davis, D.A., K.E. Singer, M. De La Luz Sierra, M. Narazaki, F. Yang, H.M. Fales, et al., Identification of carboxypeptidase $N$ as an enzyme responsible for $C$-terminal cleavage of stromal cell-derived factor-1alpha in the circulation. Blood, 2005. 105(12): p. 4561-8.

44. De Sutter, J., N.R. Van de Veire, S. Struyf, J. Philippe, M. De Buyzere, and J. Van Damme, PF$4 v a r / C X C L 4 L 1$ predicts outcome in stable coronary artery disease patients with preserved left ventricular function. PLoS One, 2012. 7(2): p. e31343.

45. Quemener, C., J. Baud, K. Boye, A. Dubrac, C. Billottet, F. Soulet, et al., Dual Roles for CXCL4 Chemokines and CXCR3 in Angiogenesis and Invasion of Pancreatic Cancer. Cancer Res, 2016. 76(22): p. 6507-6519.

46. Dubrac, A., C. Quemener, E. Lacazette, F. Lopez, C. Zanibellato, W.G. Wu, et al., Functional divergence between 2 chemokines is conferred by single amino acid change. Blood, 2010. 116(22): p. 4703-11.

47. Sarabi, A., B.K. Kramp, M. Drechsler, T.M. Hackeng, O. Soehnlein, C. Weber, et al., CXCL4L1 inhibits angiogenesis and induces undirected endothelial cell migration without affecting endothelial cell proliferation and monocyte recruitment. J Thromb Haemost, 2011. 9(1): p. 209-19. 


\section{FIGURE 1}
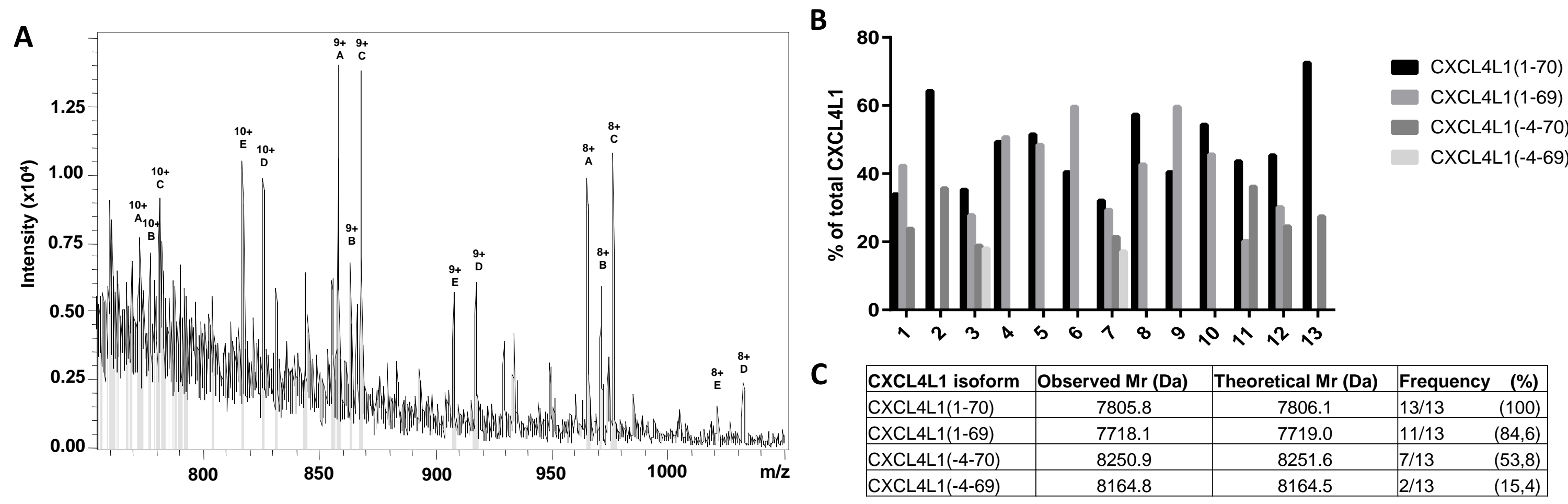
Figure 2
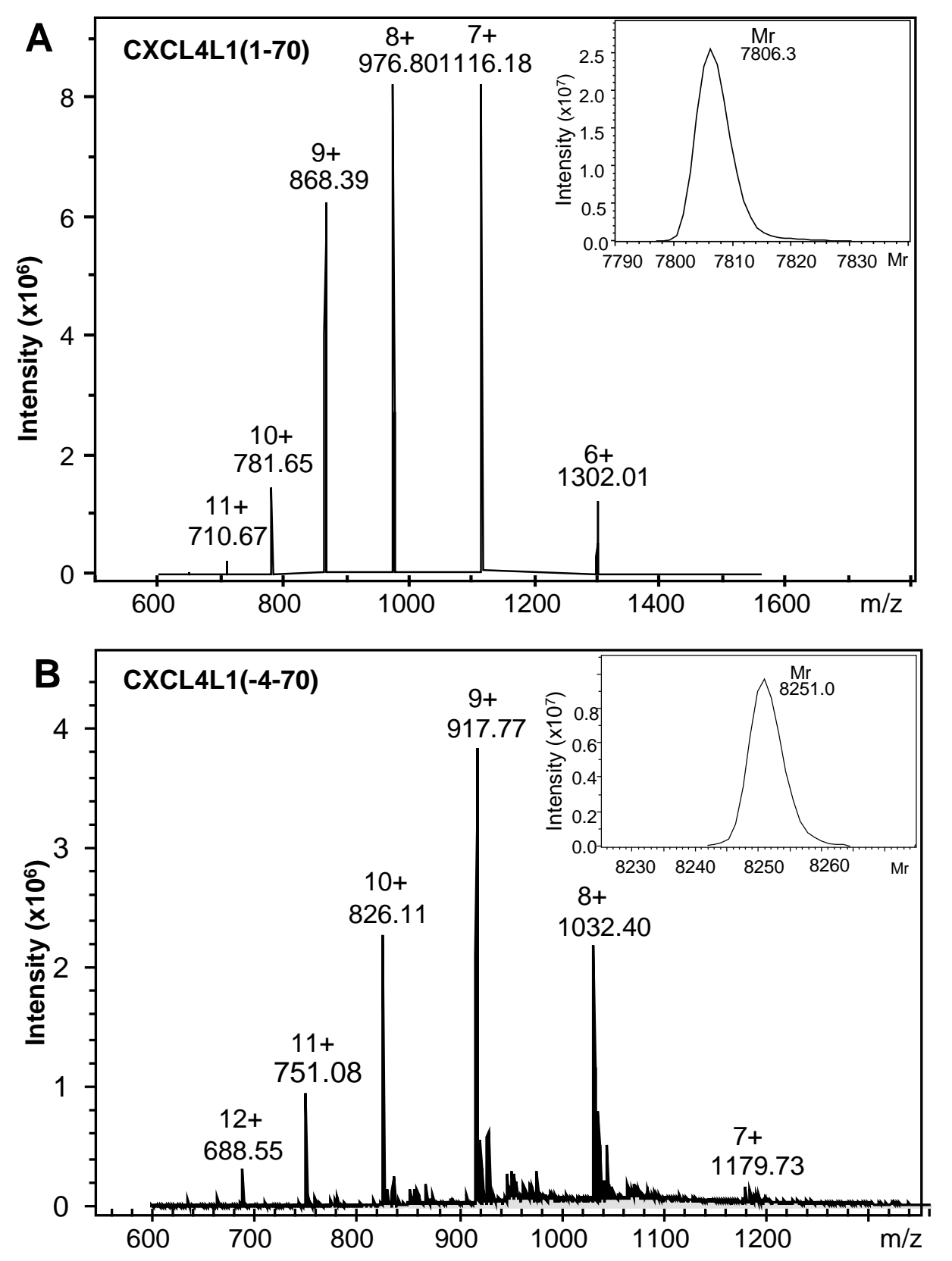
Figure 3

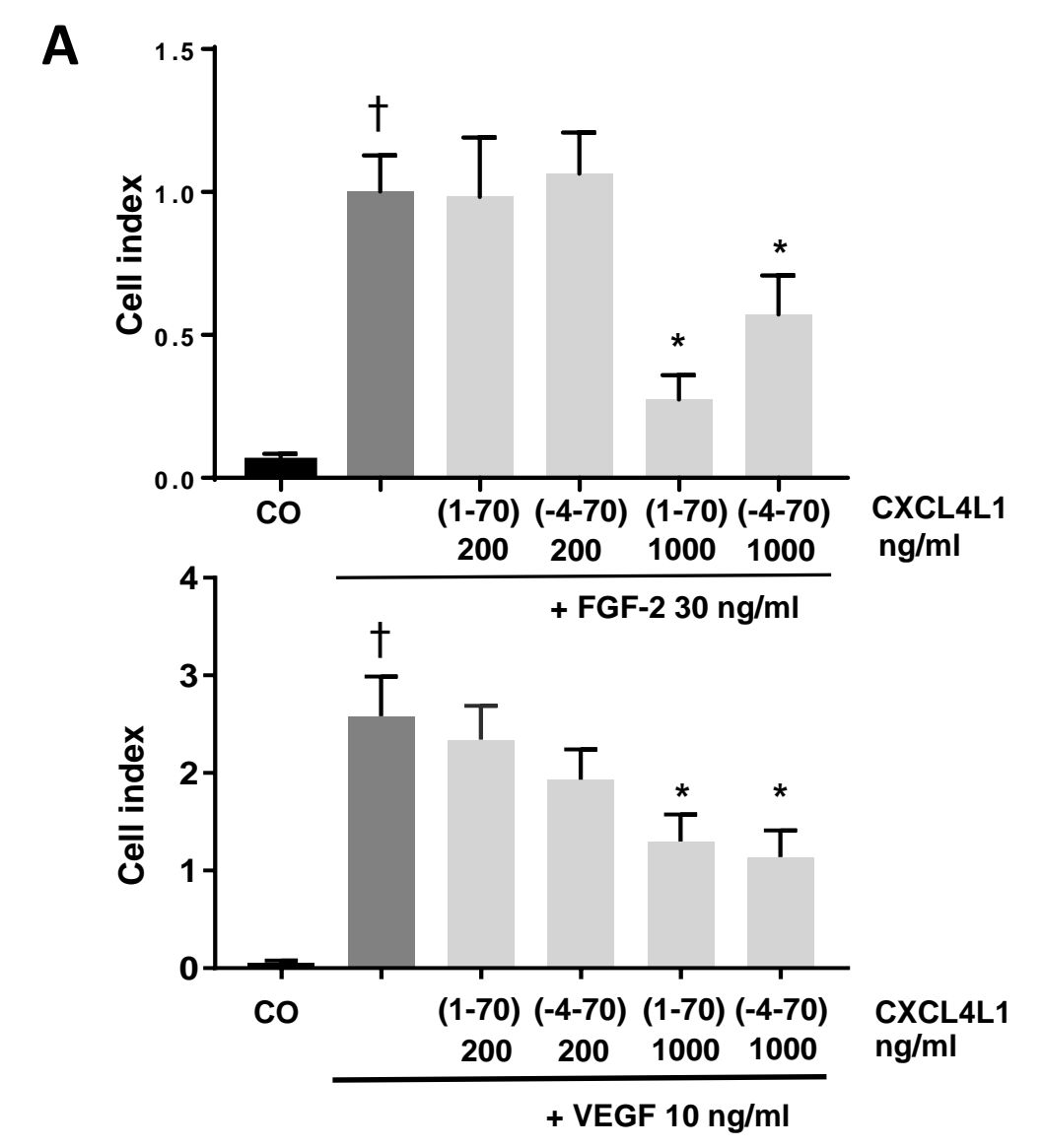


Figure 4

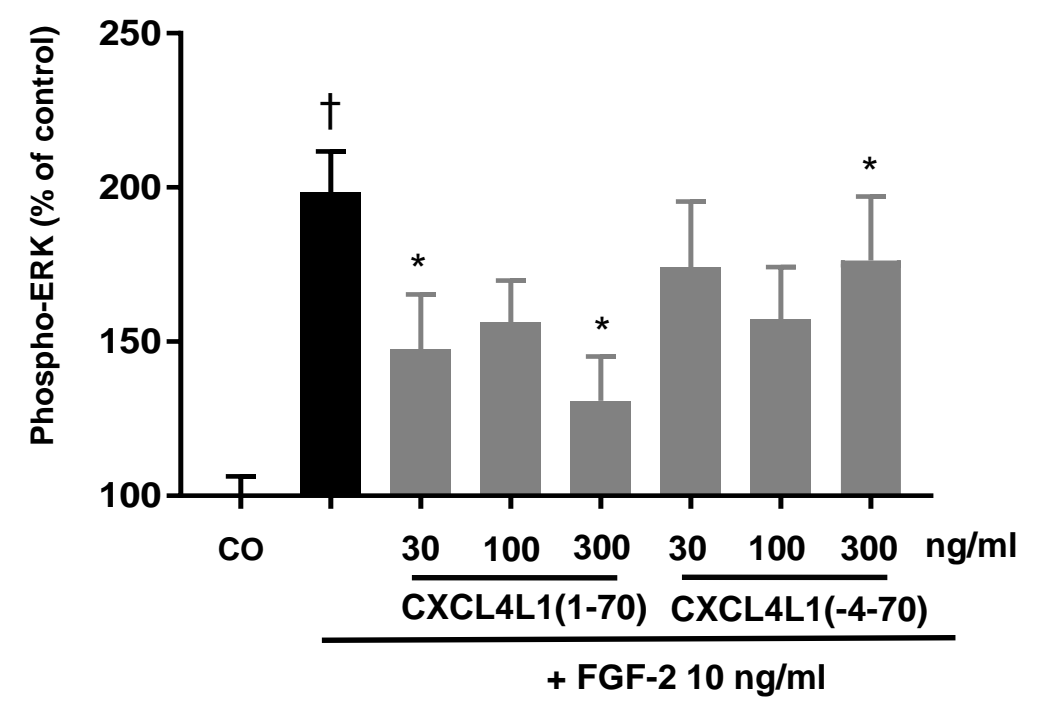


Figure 5

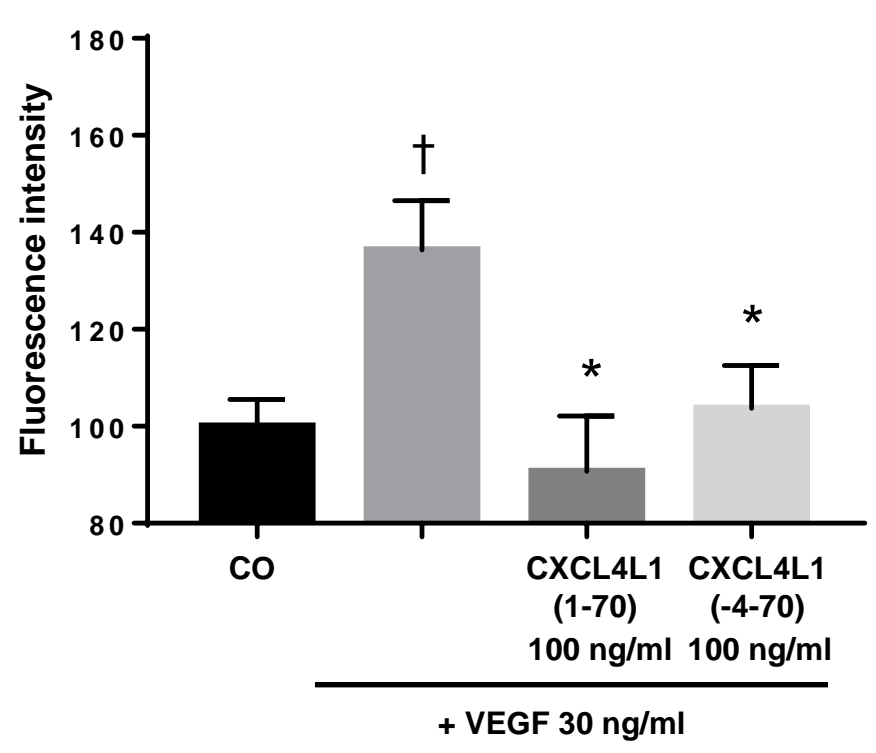


Figure 6

A

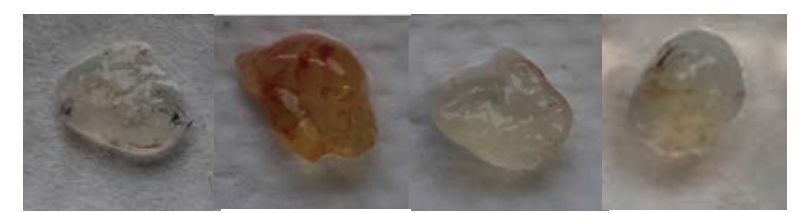

Control FGF-2 FGF-2 + FGF-2 +

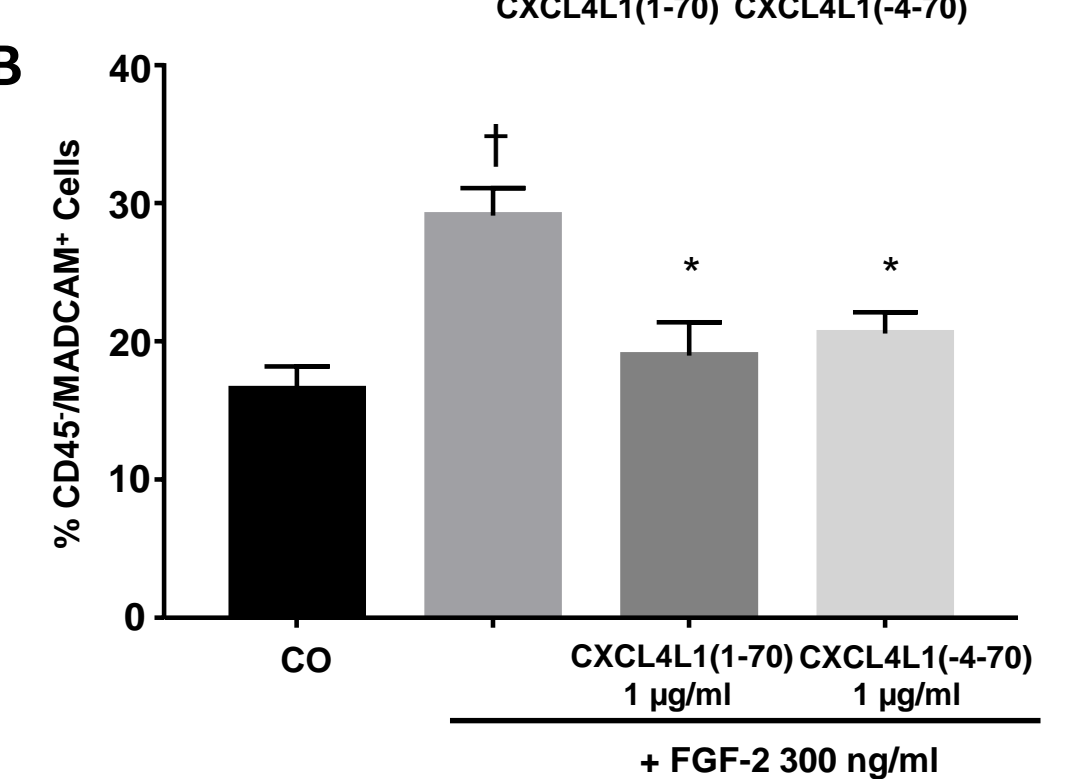


Figure 7

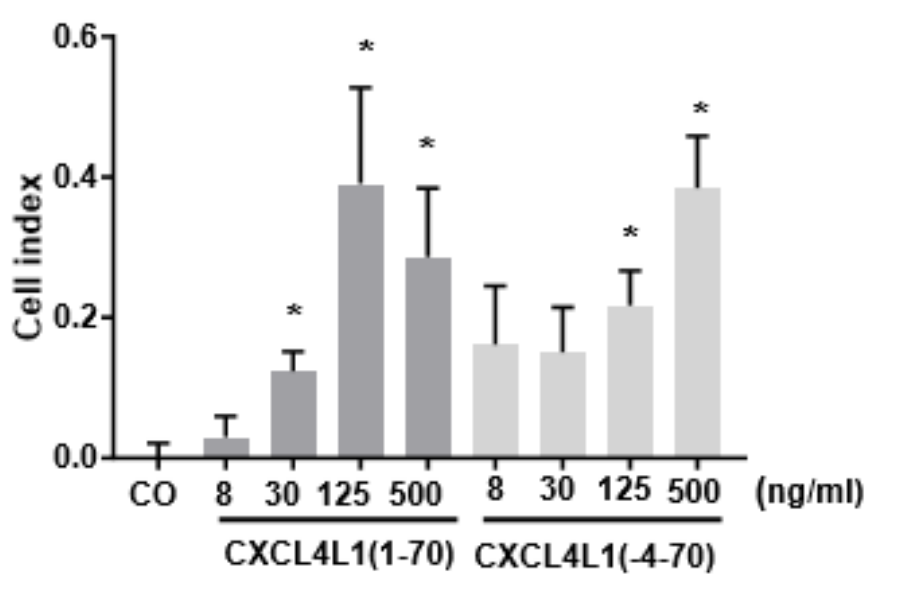


Figure 8

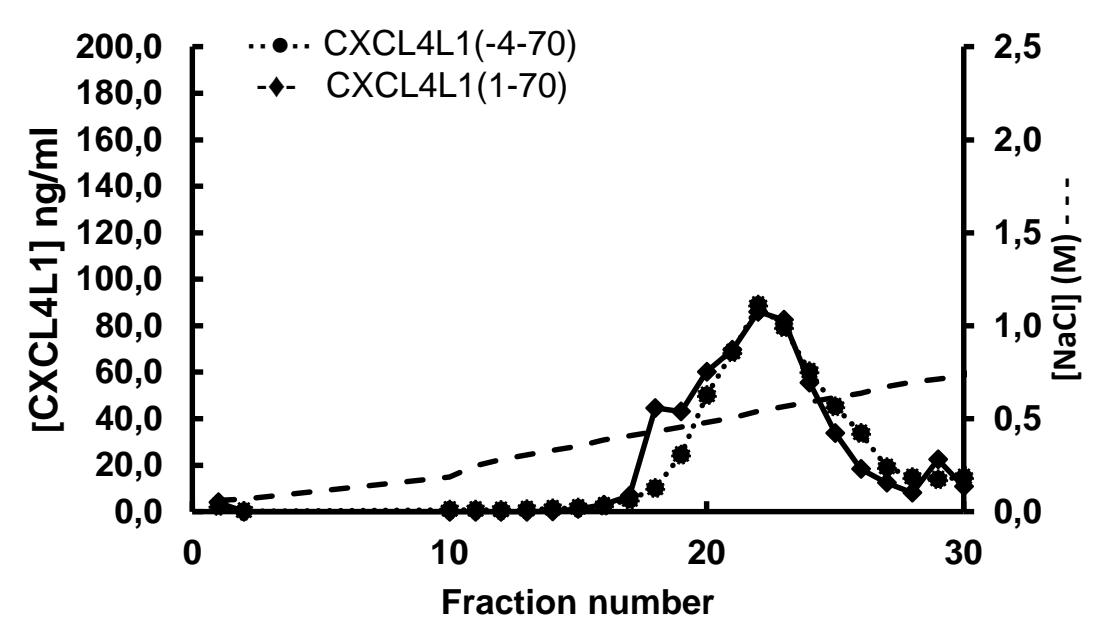

